\title{
Comparison of worm development and host immune responses in natural hosts of schistosoma japonicum, yellow cattle and water buffalo
}

Jianmei Yang, Zhiqiang Fu, Xingang Feng, Yaojun Shi, Chunxiu Yuan, Jinming Liu, Yang Hong, Hao Li, Ke Lu and Jiaojiao Lin $^{*}$

\begin{abstract}
Background: Yellow cattle and water buffalo are two of the most important natural hosts for Schistosoma japonicum in China. Previous observation has revealed that yellow cattle are more suited to the development of $S$. japonicum than water buffalo. Understanding more about the molecular mechanisms involved in worm development, as well as the pathological and immunological differences between yellow cattle and water buffalo post infection with $S$ japonicum will provide useful information for the vaccine design and its delivery procedure.
\end{abstract}

Results: The worm length $(p<0.01)$, worm recovery rate $(p<0.01)$ and the percentage of paired worms $(p<0.01)$ were significantly greater in yellow cattle than those in water buffalo. There were many white egg granulomas in the livers of yellow cattle, but fewer were observed in water buffalo at 7 weeks post infection. The livers of infected yellow cattle contained significantly increased accumulation of inflammatory cells, and the schistosome eggs were surrounded with large amounts of eosinophil infiltration. In contrast, no hepatocyte swelling or lymphocyte infiltration, and fewer white blood cells, was observed in water buffalo. The percentage of CD4 ${ }^{+} \mathrm{T}$ cells was higher in yellow cattle, while the percentage of $C D 8^{+} T$ cells was higher in water buffalo from pre-infection to 7 w post infection. The CD4/CD8 ratios were decreased in both species after challenge with schistosomes. Comparing with water buffalo, the IFN- $\gamma$ level was higher and decreased significantly, while the IL-4 level was lower and increased gradually in yellow cattle from pre-infection to $7 \mathrm{w}$ post infection.

Conclusions: In this study, we confirmed that yellow cattle were more suited to the development of S. japonicum than water buffalo, and more serious pathological damage was observed in infected yellow cattle. Immunological analysis suggested that $\mathrm{CD} 4^{+} \mathrm{T}$ cells might be an integral component of the immune response and might associate with worm development in yellow cattle. A shift from Th1 to Th2 type polarized immunity was only shown clearly in schistosome-infected yellow cattle, but no shift in water buffalo. The results provide valuable information for increased understanding of host-schistosome interactions, and for control of schistosomiasis.

\section{Background}

Schistosomiasis is one of the most serious parasitic zoonoses in the world. Approximately 365,770 people are currently infected with S. japonicum and the disease remains one of the most important public health problems in China [1]. About 46 species of mammal are known to carry natural infection with $S$. japonicum, such as rats, rabbits, dogs, cats, horses, cattle, sheep, donkeys,

\footnotetext{
* Correspondence: jjin@shvri.ac.cn

Shanghai Veterinary Research Institute, Chinese Academy of Agricultural Sciences, Key Laboratory of Animal Parasitology, Ministry of Agriculture of China, Shanghai, People's Republic of China
}

and monkeys, but only some of them are a source of human infection [2] Previous studies have revealed that the susceptibility of different types of host varies; for example, mice and yellow cattle are more sensitive than rats and water buffalo to infection with $S$. japonicum (Chinese strain) [3].

In China, the areas endemic for uncontrolled schistosomiasis are mostly in the marshland/lake and mountainous regions [4-6]. Epidemiological survey has revealed that domestic animals, especially bovines, play an important role in the transmission of schistosomiasis in these regions [7]: they are the most important reservoirs for

\section{Biomed Central}

(c) 2012 Yang et al; licensee BioMed Central Ltd. This is an Open Access article distributed under the terms of the Creative Commons Attribution License (http://creativecommons.org/licenses/by/2.0), which permits unrestricted use, distribution, and reproduction in any medium, provided the original work is properly cited. 
schistosomes and are considered the major source of infection for human schistiosomiasis [8]. Two kinds of bovine reared commonly in these endemic regions are yellow cattle (Bos taurus) and water buffalo (Bubalus bubalis). These animals are naturally infected with schistosomes and spread more eggs into the environment than human and other animal hosts, and are considered to be the main sources of transmission of schistosomiasis in most lake and marshland endemic areas $[9,10]$.

There is a significant difference in the rate of development between worms from yellow cattle and water buffalo infected with S. japonicum [11]. He et al. infected mice, rats, guinea pigs, rabbits, goats, sheep, pigs, water buffalo, yellow cattle, horses and another 12 kinds of animal with S. japonicum under identical conditions, and observed the development of parasites in these hosts for up to 60 weeks. The results showed that the development rates of $S$. japonicum in these hosts were quite different, with the highest infection rate of $60.3 \%$ in goats, $43.6 \%$ in yellow cattle, and $1 \%$ in water buffalo and horses [12]. Given that yellow cattle and water buffalo both act as important natural hosts for schistosomes in endemic areas, understanding more about the molecular mechanisms involved in worm development, as well as the pathological and immunological differences between yellow cattle and water buffalo pre and post infection with $S$ japonicum will provide useful information for the design of a vaccine and its delivery procedure. However, relatively few studies on the mechanism underlying the differences in patterns of infection among hosts have been reported, and the relevant immune mechanism is not clear. In this study, yellow cattle and water buffalo were artificially infected with $S$. japonicum cercariae, and at different times post infection( 0 weeks [w], 2w, 4w, 7w), the $\mathrm{CD}^{+}$and $\mathrm{CD} 8^{+} \mathrm{T}$ cell subsets and the intracellular cytokines interferon- $\gamma($ IFN- $\gamma)$ and interleukin-4(IL-4) in the peripheral blood, as well as specific serum IgG antibodies, were detected and analyzed. In addition, the morphology and development rate of the worms were compared between the two host species. The study provides basic information for increasing understanding of the differences in schistosome infection between two native hosts, the susceptible host yellow cattle and the less susceptible water buffalo.

\section{Methods}

\section{Animals and parasites}

Six yellow cattle and six water buffalo, which were male, 15-18 months old, and free of parasitic and other infectious diseases, were used for experimental infection. The animals were purchased from areas non-endemic for schistosomes and had similar body weight. All animals were housed in covered pens, cared for by trained animal keepers and fed with hay and a commercial pelleted ration. Water and mineralized salt were available ad libitum. Cercariae of S. japonicum (Chinese strain) were obtained from the snail-maintenance room at Shanghai Veterinary Research Institute, Chinese Academy of Agricultural Sciences. The cercariae were shed at $20-25^{\circ} \mathrm{C}$ before challenge to ensure maximum vitality. The study protocol was approved by the Animal Care and Use Committee of the Shanghai Veterinary Research Insitute, Chinese Academy of Agricultural Sciences (CAAS). The use of experimental animals in this study was approved under Project A005 by the Animal Ethics Committee of the Shanghai Veterinary Research Insitute, CAAS.

\section{Experimental infection and the collection of blood samples}

Each of the yellow cattle and water buffalo was challenged percutaneously with 1000 and 2000 cecariae of $S$. japonicum, respectively, through the upper back using the cover glass method [13]. Before infection and at $2 \mathrm{w}$, $4 \mathrm{w}$ and $7 \mathrm{w}$ post infection, blood samples were collected from each animal using ordinary vacuum tubes containing sterile anticoagulant heparin. The blood samples for flow cytometry analysis were treated in 5 hours; serum separation was completed within 24 hours.

\section{Animal pathology observation and collection of parasite and tissue samples}

The animals were sacrificed 7 weeks post infection and the parasites were perfused through the hepatic portal vein. The male and female worms were detached manually, counted, and the length of the worms was measured by the same person. The remaining worms were fixed in $4 \%$ paraformaldehyde solution after washing with phosphate buffer saline (PBS). The livers of infected hosts were harvested, dissected into $1.5 \mathrm{~cm} \times 1.5 \mathrm{~cm} \times 0.3 \mathrm{~cm}$ pieces for sectioning, and fixed in $10 \%$ neutral formalin

\section{Preparation of paraffin sections}

The formalin-fixed samples were dehydrated in ethanol, cleared with xylene and embedded in paraffin wax. Sections (6 $\mu \mathrm{m}$ thick) were stained with HE (hematoxylin and eosin) and observed using a light microscope.

\section{Detection and analysis of the proportion of $\mathrm{CD}^{+}$and $\mathrm{CD}^{+}{ }^{+}$cell subsets as well as intracellular cytokines IFN- $\gamma$ and IL-4 in the peripheral blood \\ Antibodies, reagents and equipment}

Monoclonal antibodies specific to surface markers and intracellular cytokines, including anti-bovine CD4 FITC (mouse IgG2a:clone CC8), anti-bovine CD8 Alexa Flour 647 (mouse IgG2a:clone CC63), anti-bovine IFN- $\gamma$ R. phycoerythrin (RPE) (mouse IgG1:clone CC302), antibovine IL4 R.phycoerythrin (RPE) (mouse IgG2a:clone 
CC303), anti-bovine CD4 RPE (IgG2a:clone CC8), antiCD3 FITC(IgG1:clone CD3-12), as well as control antibodies for mouse IgG2a and mouse IgG1, were purchased from AbD Serotec (Oxford, UK). Phorbo 12-myristate 13-acetate (PMA), ionomycin, monensin, paraformaldehyde, and saponin were bought from Sigma-Aldrich (Germany); RPIM-1640 medium, FBS, erythrocyte lysis buffer, penicillin/streptomycin, and fixation and permeabilization buffer were from BD (Becton Dickinson, USA); the FACScalibur flow cytometer was obtained from BD (Becton Dickinson, USA); the $\mathrm{CO}_{2}$ cell incubator was from HERA GmbH (Germany).

\section{Detection and analysis of the proportion of $C D 4^{+}$and $C D 8^{+}$} $T$ cell subsets

To remove red blood cells (RBCs), $0.5-1 \mathrm{~mL}$ heparinized whole blood was added to $15 \mathrm{~mL}$ erythrocyte lysis buffer, mixed for 3-5 min, centrifuged at 800-1000 rpm for $5 \mathrm{~min}$, and washed twice with PBS. Vital cells were counted by means of trypan blue dye exclusion staining and adjusted to $1 \times 10^{9}$ cells/L. Each sample was divided into three parallel tubes with $100 \mu \mathrm{l}$ cell suspension in each tube.

The procedure for flow cytometry (FCM) staining followed the method described by Liu [14]. Briefly, the cells of each sample were stained with anti-CD4 RPE and antiCD3 FITC, or anti-CD8 Alexa Flour 647 and anti-CD3 FITC. The tubes were mixed thoroughly, incubated at room temperature for 20-30 min in the dark, and the percentages of the CD3 + CD4+ and CD3 + CD8+ T cell subsets were recorded using a FACScalibur flow cytometer (BD, USA). Analyses of the FCM data were performed using CellQuest software.

\section{Detection and analysis of the level of intracellular cytokines} IFN- $\gamma$ and IL-4

Heparinized whole blood and RPMI 1640 medium were mixed in a ratio of $1: 1$, and RBCs were treated as mentioned above. The cell mixture was washed twice with RPMI 1640 medium and grown in complete RPMI 1640 medium containing $2 \mathrm{mM}$ L-glutamine, $100 \mathrm{U}$ of penicil$\mathrm{lin} / \mathrm{mL}$, and $0.1 \mathrm{mg} / \mathrm{mL}$ streptomycin in an incubator at $37^{\circ} \mathrm{C}$ with $5 \% \mathrm{CO}_{2}$. Intracellular staining was performed as described previously [15]. The cells were adjusted to a concentration of $1 \times 10^{7} / \mathrm{mL}$ in complete RPMI 1640 medium. For cytokine assays, the procedures were performed according to the manufacturer's protocol. Briefly, about $2 \times 10^{6}$ cells were set in each tube, the cells were stimulated in the presence of PMA $(25 \mu \mathrm{g} / \mathrm{L}$, ionomycin $(1 \mathrm{mg} / \mathrm{L})$, and monensin $(2 \mathrm{mg} / \mathrm{L})$ for $6 \mathrm{~h}$, then incubated with surface marker antibodies in the dark for $10 \mathrm{~min}$. Fixation and permeabilization buffer were added, and the cells were washed in PBS again and stained with intracellular antibodies at room temperature for 20-30 $\mathrm{min}$ in the dark. Finally the cells were washed and detected by flow cytometry.

\section{Detection and analysis of specific serum IgG antibodies}

The level of specific antibodies against schistosome egg antigen (SEA) was determined by enzyme-linked immunosorbent assay(ELISA). The SEA was prepared from the livers of rabbits infected with $S$. japonicum as described before; the concentration of SEA was measured using the bicinchoninic acid (BCA) method (Pierce Europe B.V., The Netherlands). Microtiter plates (Maxisorp, Nunc, UK) were coated with SEA $(10 \mu \mathrm{g} / \mathrm{mL})$ in $0.1 \mathrm{M}$ carbonate buffer, pH $9.6(100 \mu \mathrm{L} /$ well $)$ and incubated overnight at $4^{\circ} \mathrm{C}$, before blocking with $8 \%$ pig serum in PBS with $0.05 \%$ Tween 20 at $37^{\circ} \mathrm{C}$ for $1 \mathrm{~h}$. Subsequently, $100 \mu \mathrm{L}$ of test sera diluted at 1:200 was added in triplicate and incubated for $60 \mathrm{~min}$ at $37^{\circ} \mathrm{C}$. Following this, $100 \mu \mathrm{L}$ of horseradish peroxidase-conjugated rabbit anti-cow IgG (Dakocytomation, Cambridgeshire, UK) was added with different dilution and incubated for $60 \mathrm{~min}$, then $100 \mu \mathrm{L}$ of the soluble type TMB substrate solution (Tiangen, Beijing) was added and incubated for $10 \mathrm{~min}$. The reaction was stopped by addition of $50 \mu \mathrm{L}$ of $2 \mathrm{M}$ sulfuric acid. The optical density (OD) was read at $450 \mathrm{~nm}$ in an ELISA reader (BioTek, USA). After each step, the plates were washed with PBS-0.1\% Tween 20 three times for 5 min each.

\section{Statistical analysis}

Statistical differences between cattle and water buffalo were determined using a Student's $t$-test and expressed as $p$-values. A value of $p<0.05$ was considered statistically significant.

\section{Results}

Histopathological differences in the livers of yellow cattle and water buffalo infected with S. Japonicum

Yellow cattle and water buffalo were sacrificed 7 weeks post infection and the differences in livers between yellow cattle and water buffalo were observed. The results revealed that the livers from yellow cattle were dark red with many white egg nodules, composed of many egggranulomas, while the livers from water buffalo were red with few or no egg nodules (Figure 1).

The histological sections from livers of infected yellow cattle showed that some hepatocytes displayed mild swelling, a large number of inflammatory cells were seen to be infiltrating and aggregating, including eosinophils and lymphocytes, and typical striped eosinophilic deposits were seen. This is known as the Hoeppli phenomenon [16], and is formed by immuno-precipitation of egg antigens and host antibodies in the liver. Moderate to severe fibrous perihepatitis and a number of white migratory tracts in the hepatic surface and parenchyma were observed, which were composed of an abundant infiltrate of eosinophils and macrophages, some of them with a proliferation of fibrous connective tissue (Figure 2, A, C, E). 

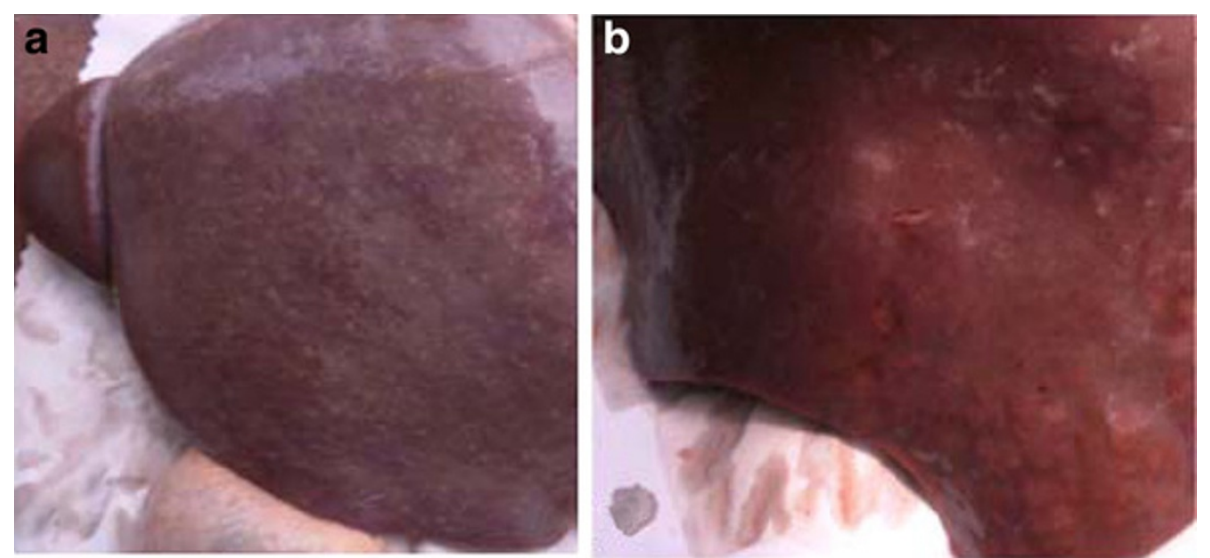

Figure 1 Comparison of liver pathological changes. Livers from two natural hosts at 7w post infection: (A) yellow cattle; (B) water buffalo.

Compared with the yellow cattle, the structural integrity of the hepatic lobules was intact in the livers of infected water buffalo, there was actinomorphous distribution of hepatic cord centered on central veins, polygonal hepatocytes, no edema, no inflammatory cell infiltrated, and only scattered neutrophils and monocytes (Figure 2, B, D, F).

\section{Differences in morphology and development rate} between worms from yellow cattle and water buffalo The animals were sacrificed and the parasites were perfused through the hepatic portal vein 7 weeks post infection. The average worm recovery rate from water buffalo was only $2.9 \%$, around one-tenth of that of yellow cattle (29.7\%). Attenuated parasite development was observed in water buffalo, which was evidenced by reduced numbers of paired worms and changes in morphology. The percentage of paired worms from water buffalo was significantly fewer than those from yellow cattle $(p<0.01)$. The length and width of the worms from the two hosts were compared, and this revealed that no significant difference was seen in the width, but both male and female adult worms from yellow cattle were significantly longer than those from water buffalo $(p<0.01)$, and the average length of female worms from yellow cattle was nearly twice as long as those from water buffalo (see Figure 3).

\section{Comparison of the proportion of $\mathrm{CD}^{+}$and $\mathrm{CD}^{+} \mathrm{T}$ cell subsets in yellow cattle and water buffalo infected with \\ S. Japonicum}

The proportion of $\mathrm{CD}^{+}$and $\mathrm{CD}^{+} \mathrm{T}$ cell subsets in the peripheral blood from animals before and after challenge with $S$. japonicum was determined using flow cytometry. The results showed that the percentage of $\mathrm{CD} 4^{+} \mathrm{T}$ cells in yellow cattle was always significantly higher than that in water buffalo from pre-infection to $7 \mathrm{w}$ post infection. The proportion of $\mathrm{CD}^{+} \mathrm{T}$ cells was significantly decreased after yellow cattle were challenged with schistosomes, and was significantly decreased at $2 \mathrm{w}$ post infection, increased slightly at $4 \mathrm{w}$ post infection, then decreased again at $7 \mathrm{w}$ post infection in yellow cattle. However, the change in the proportion of $\mathrm{CD}^{+} \mathrm{T}$ cells was not as significant as that seen in $\mathrm{CD}^{+} \mathrm{T}$ cells before and post infection with schistosomes in yellow cattle. The results also showed that the percentage of $\mathrm{CD}^{+} \mathrm{T}$ cells in water buffalo was significantly higher than that in yellow cattle from pre-infection to $7 \mathrm{w}$ post infection. The proportion of $\mathrm{CD}^{+} \mathrm{T}$ cells was increased after water buffalo were challenged with schistosomes; it had increased significantly at $2 \mathrm{w}$ post infection, and continued to increase at $4 \mathrm{w}$ post infection, then decreased slightly at $7 \mathrm{w}$ post infection. A lower level of $\mathrm{CD}^{+} \mathrm{T}$ cells and no significant change was observed before and after challenge with schistosomes in water buffalo (Figure 4).

The ratio of CD4/CD8 cells in yellow cattle and water buffalo pre and post infection with schistosomes were compared and analyzed. The ratio was always higher in yellow cattle than in water buffalo. The ratio of CD4/ CD8 cell was significantly decreased when yellow cattle were infected with $S$. japonicum, but it was lower and no significant decrease was observed in water buffalo (Figure 5).

\section{Comparison of the level of intracellular cytokines IFN- $\gamma$} and IL-4 between yellow cattle and water buffalo infected with S. Japonicum

The proportion of intracellular cytokines IFN- $\gamma$ and IL-4 produced by peripheral blood cells in yellow cattle and water buffalo pre and post infection with $S$. japonicum were detected. At $2 \mathrm{w}$ post infection, the percentage of IFN- $\gamma$ decreased significantly in yellow cattle, then increased to a level near to the pre-infection level at $4 \mathrm{w}$ post infection, and decreased to a very low level at $7 \mathrm{w}$ post infection. The level of IL-4 was very low pre-infection and at $2 \mathrm{w}$ post infection in yellow cattle, and a low 

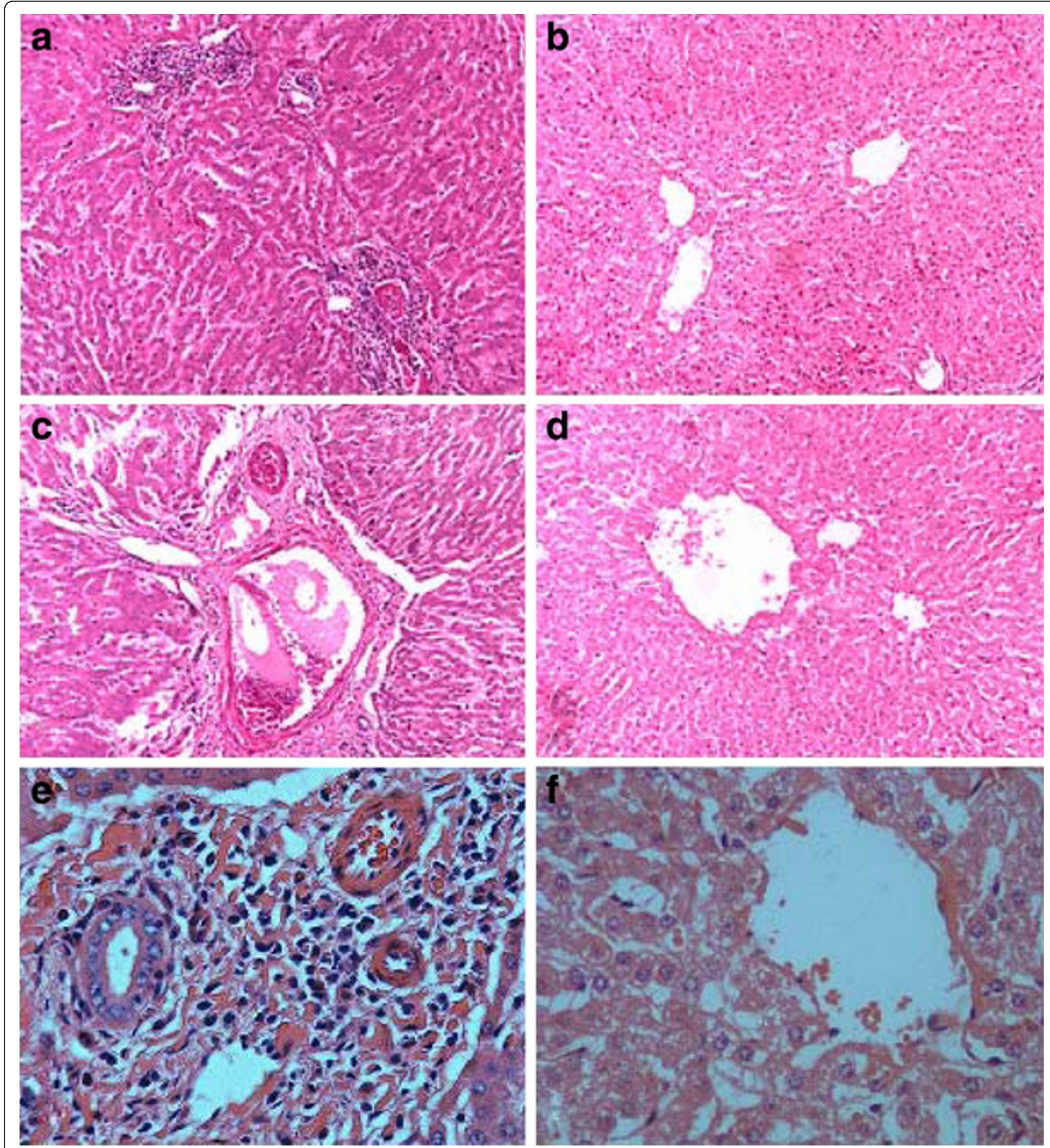

Figure 2 Micrographs of HE staining of the liver tissue sections. The liver tissue sections from two natural hosts: yellow cattle (A, C, E) and water buffalo $(B, D, F), A, B, C, D$ are $10 \times 10$ magnification, $E$ and $F$ are $10 \times 40$ magnification.

IL-4 level was detected at 4w and 7w in yellow cattle challenged with schistosomes. The level of IFN- $\gamma$ in preinfection water buffalo was much lower than that in yellow cattle; the level of the cytokine increased in water buffalo $2 \mathrm{w}$ post infection, then decreased to a similar level to that in pre-infected animals, and continued to decrease to an even lower level at $7 \mathrm{w}$ post infection. The IL-4 level was much higher in pre-infected water buffalo than in yellow cattle, but subsequently the cytokine decreased to a very low level at $2 \mathrm{w}$ post infection, increased at $4 \mathrm{w}$ and decreased at $7 \mathrm{w}$ post infection in water buffalo (Figure 6). 
(E) female worms, upper from water buffalo and lower from yellow cattle. Level of significance when compared to water buffalo group, ${ }^{* *} p<0.01$. The number of worms compared per group was at least $\mathrm{n}=50$ for females and males, respectively, and included worms

from all animals.

\section{Specific antibody response post infection}

The specific serum IgG antibody was detected by ELISA in yellow cattle and water buffalo pre and post infection with S. japonicum. The results showed that the antibody response in water buffalo was at a low level until $7 \mathrm{w}$ post infection; while the level of SEA specific IgG antibodies was increased gradually in yellow cattle after infection with schistosomes in yellow cattle and and reached a higher level at $7 \mathrm{w}$ post infection (Figure 7).

\section{Discussion}

Increased understanding of the development of schistosomes in yellow cattle and water buffalo, and elucidation of the related molecular mechanisms involved in S. japonicum infection caused by these two important natural hosts will provide useful information for the design and delivery of a vaccine against schistosomiasis. In this study, we confirmed that yellow cattle were more suited to the development and survival of schistosomes than water buffalo. Studies have shown that in some animal hosts, such as rats, pigs, and water buffalo, in the period after $S$. japonicum infection, the worm burden drops sharply, mainly owing to parasite clearance by the immune system and non-immune system factors, called the self-cure phenomenon $[12,17,18]$. This phenomenon is not found in mice, yellow cattle and some other schistosome-susceptible hosts. Several epidemiological surveys have reported that the natural infection of yellow cattle with schistosomiasis is obviously more severe than that of water buffalo [5,19-21]. But water buffalo reared in endemic areas have more chances and longer time to contact with the contaminated water, that is, there are more chances for water buffalo to get infection and reinfection than yellow cattle and other animals, so although water buffalo are less suitable for the development of S. japonicum, they still retained a higher infection rate for this parasite. For many diseases, genetically determined host susceptibility can play a role in the clinical outcome. The pathogenesis of schistosomiasis and the apparent involvement of the immune response in both susceptibility and resistance have proved complex and difficult to understand, and therefore more research on these topics is required. The characterization of schistosome responses to host factors and the host factors that elicit/prevent developmental responses in schistosomes is important and also warrants further investigation $[22,23]$. 


\section{yellow cattle}

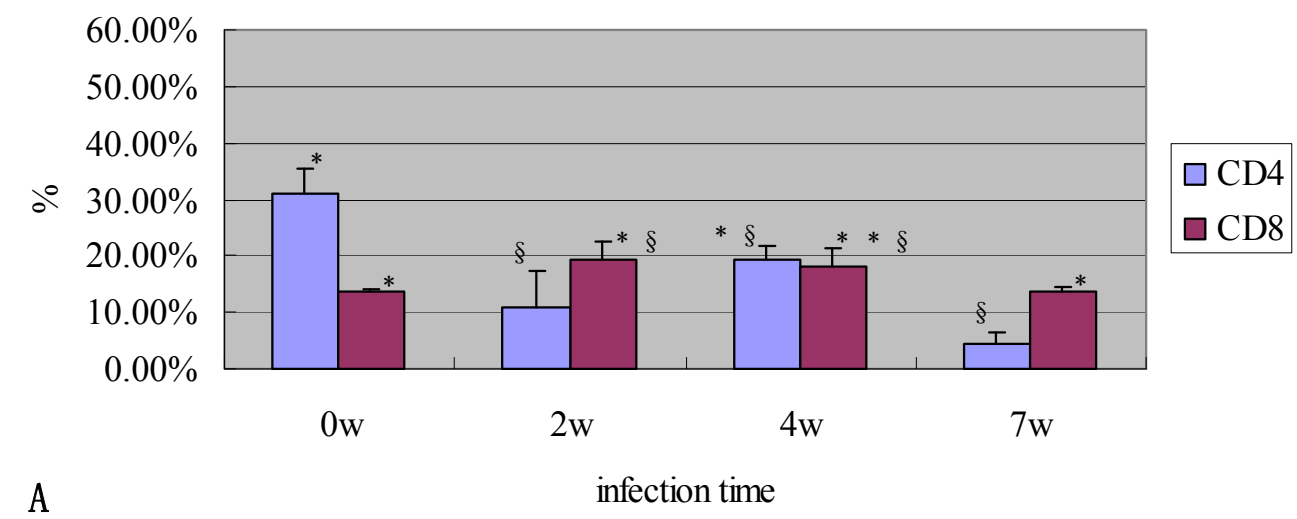

\section{water buffalo}

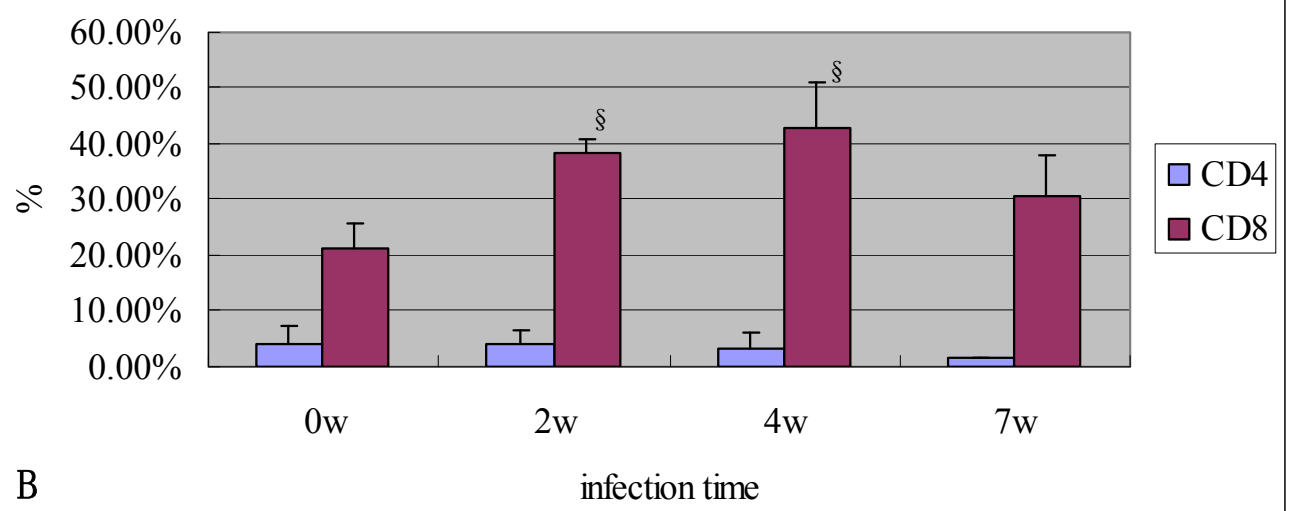

Figure 4 Percentage of CD4 and CD8 T cells detected by flow cytometry pre and post infection. (A) yellow cattle; (B) water buffalo. Level of significance when compared to water buffalo group at the same time, ${ }^{*} p<0.05,{ }^{* *} p<0.01$. Level of siginificance when compared to $0 \mathrm{~W}$ in each host, $\S p<0.05$.

The tissue immune response and pathological damage caused by $S$. japonicum infection were observed in this study. The results revealed that the disease was much more serious in yellow cattle than in water buffalo; it seems that yellow cattle produce a stronger immune response than water buffalo, but the molecular mechanism for this phenomenon is still unknown.

It has been reported that schistosomes require signals from the host's immune system in order to develop fully into egg-producing adults $[24,25]$. In the present study, we observed that the percentage of $\mathrm{CD}_{4}^{+} \mathrm{T}$ cells or the ratio of CD4/CD8 in yellow cattle was significantly higher than those in water buffalo from pre-infection to $7 \mathrm{w}$ post infection (Figure 4 and 5). This may be one explanation why schistosomes grow better in yellow cattle than in water buffalo. It has been supposed that a highly evolved relationship exists between schistosomes and their hosts that may include parasite exploitation of host endocrine and immune signals [26,27]. Recent studies have confirmed, further, that $S$. mansoni failed to receive appropriate signals from the host immune system after infection of immunodeficient mice (RAG-1 ${ }^{-/}$), which resulted in the appearance of attenuated forms. Hepatic $\mathrm{CD} 4^{+} \mathrm{T}$ lymphocyte populations were identified as an integral component of the immune signal recognized by the parasite. Reconstitution with $\mathrm{CD} 4^{+}$cells rescued schistosome development during prepatency, which resulted in larger parasites, higher levels of pairing, and dramatically increased levels of egg production. Depletion of $\mathrm{CD} 4^{+}$cells but not $\mathrm{CD} 8^{+}$ cells from wild-type mice in vivo by the administration of 


\section{$\mathrm{CD} 4 / \mathrm{CD} 8$}

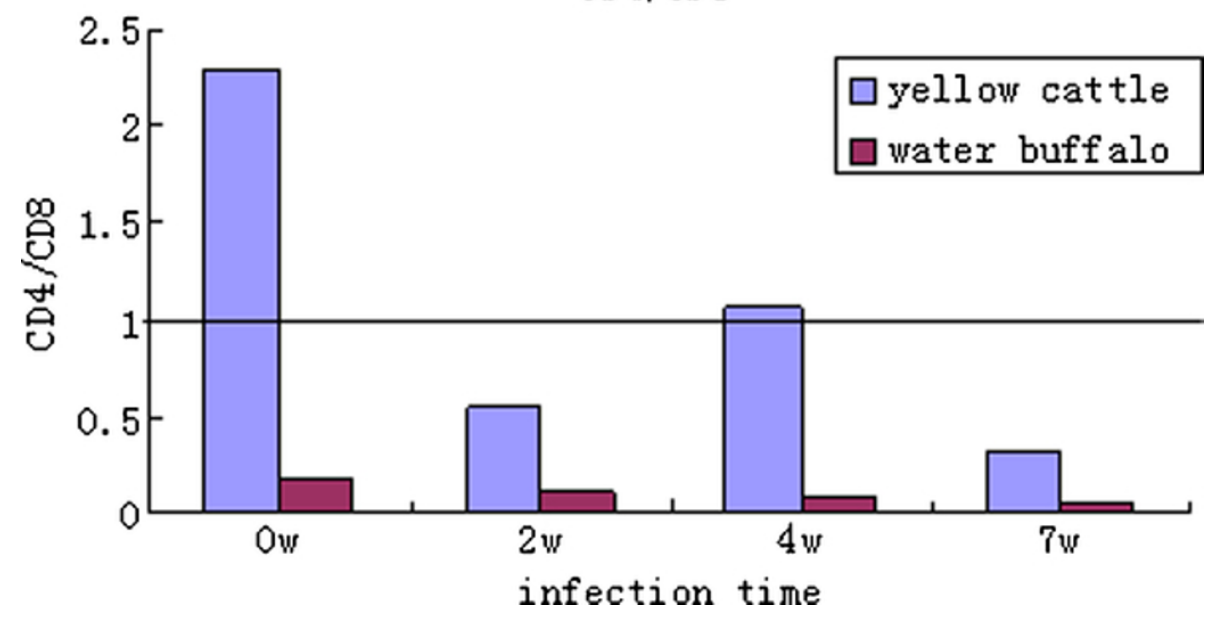

Figure 5 The ratio of CD4/CD8 cells in yellow cattle and water buffalo pre and post infection.
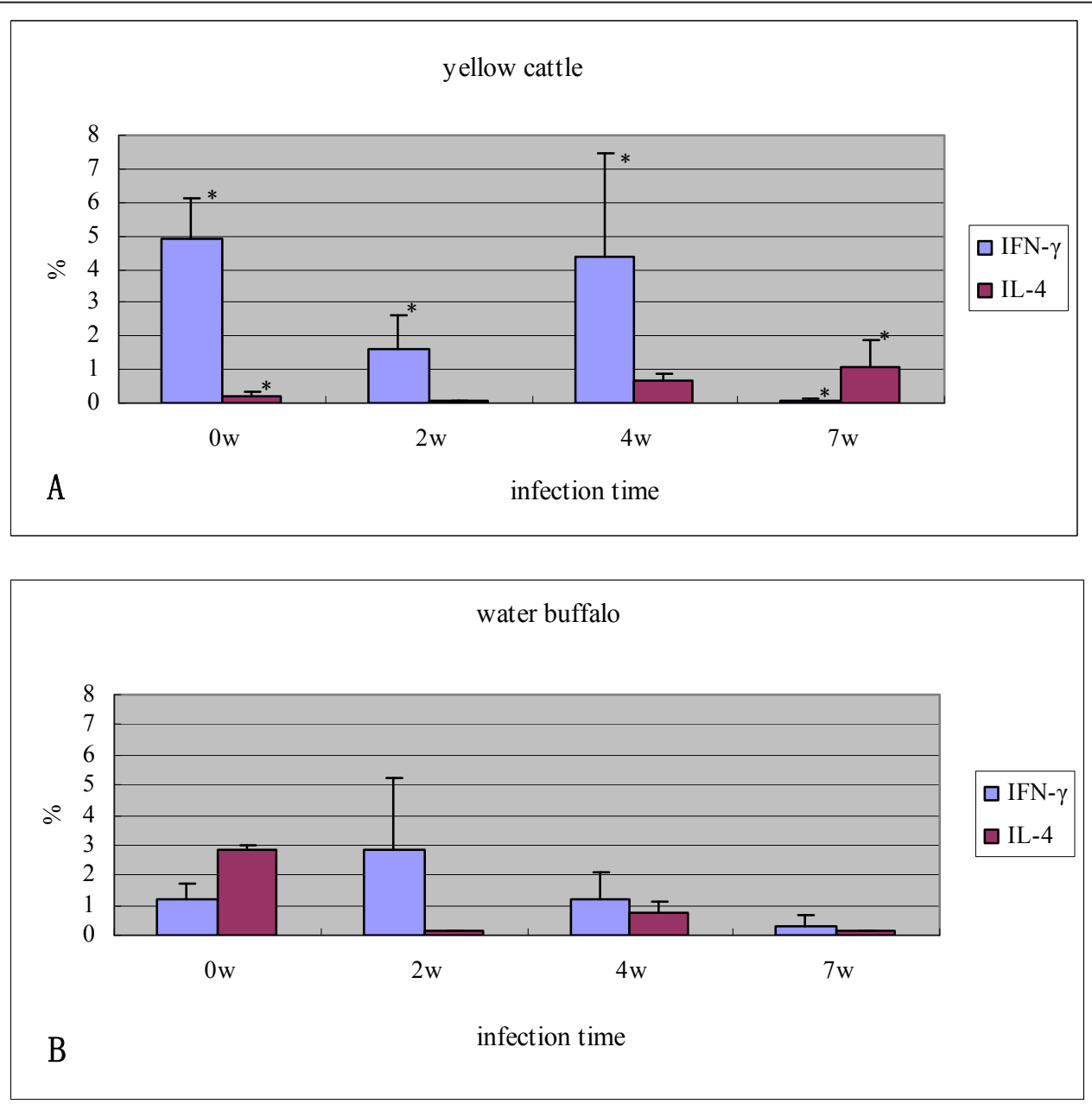

Figure 6 Percentage of IFN- $\boldsymbol{\gamma}$ and IL-4 positive cells detected by flow cytometry pre and post infection. yellow cattle; (B) water buffalo. Level of significance when compared to water buffalo group at the same time, ${ }^{*} p<0.05$. 


\section{The serum IgG antibodies were detected by ELISA method pre/post-infection}

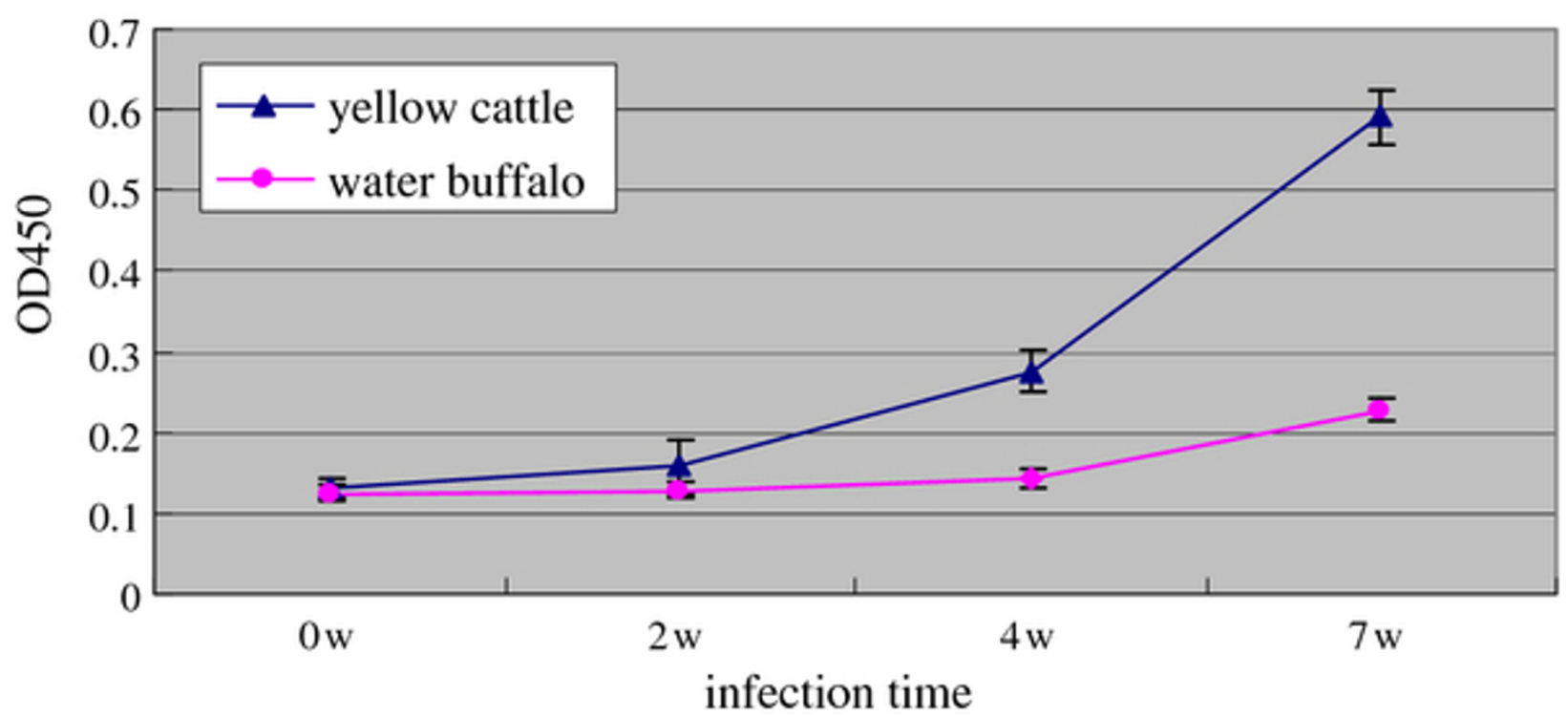

Figure 7 The specific serum IgG antibody response in yellow cattle and water buffalo detected by ELISA.

specific antibodies reduced egg production by the parasites. Therefore, the authors suggested that $\mathrm{CD} 4^{+} \mathrm{T}$ lymphocytes were responsible for promoting early schistosome development [24]. CD4 ${ }^{+} \mathrm{T}$ lymphocytes have also been found to be necessary for the development of a parasitic protozoan: Houpt et al. reported that the depletion of $\mathrm{CD}^{+}$cells diminished both parasite burden and inflammation significantly in the mouse model of amebic colitis [28]. Lamb et al. further found that schistosomes co-opt innate immune signals to facilitate worm development, and that $\mathrm{CD} 4^{+} \mathrm{T}$ cells influence the parasites indirectly by modulating monocyte/macrophage function [29]. In this study, our results support the hypothesis proposed by Davies et al. and other investigators, and suggest that $\mathrm{CD} 4^{+} \mathrm{T}$ lymphocytes might be an integral component of the immune response and might related with worm development in yellow cattle, a natural host of the schistosome, but more investigations should be carried out to confirm it and whether susceptibility is correlated with the differences in the innate immune system between yellow cattle and water buffalo also needs further investigation.

Our observations also showed that the proportion of $\mathrm{CD} 4^{+} \mathrm{T}$ cells in yellow cattle decreased, the $\mathrm{CD} 8^{+} \mathrm{T}$ cells proportion in water buffalo increased, and the CD4/CD8 ratios were decreased in both species after challenge with schistosomes. The observations in yellow cattle were consistent with a previous report on mice, another schistosome-sensitive host [30]. Subsets of $\mathrm{CD}^{+} \mathrm{T}$ cells are characterized by their cytokine-production profiles. Th1 cells produce primarily IFN- $\gamma$, and generally provide protection against intracellular pathogens, whereas Th2 cells produce mainly IL-4, IL-5 and IL-13, and are important for immunity against helminth parasites. During the schistosome infection process, the immune response includes at least three stages. In the first 3-5 weeks, mainly immature parasites migrate inside the host, which shows a dominant Th1-type response. In the following 5-6 weeks, the worms mature and begin spawning in pairs, and the immune response changes significantly: the Th1-type response decreases, but the Th2-type response becomes significantly enhanced. This response is stimulated mainly by the egg antigen. In chronic infection, after a long period of time with the continuous generation of parasite eggs, the Th2-type response is altered by the eggs and the egg granulomas become smaller than before [31]. A study in mice found that the Th2-type cell-mediated granulomatous response appears to protect liver cells, but severe fibrosis occurs during the development of human schistosomiasis [32]. From the acute phase to the chronic phase, the immune response against the infection changes from the Th1-type to the Th2-type, and induces a significant increase of $\mathrm{CD} 4{ }^{+} \mathrm{CD} 25^{+}$regulatory $\mathrm{T}$ cells, which have a broad immune suppression function [33]. In this study, we observed that, in yellow cattle, the IFN- $\gamma$ level was higher pre-infection and at 4 weeks post infection, then decreased significantly and was at a very low level 7 weeks post infection. In addition, the level of IL-4 was very low pre-infection and $2 \mathrm{w}$ post infection; IL-4 was also expressed at a lower level at $4 \mathrm{w}$ but had increased at $7 \mathrm{w}$ post challenge with schistosomes. Th1 polarized immunity during the 
early phase of infection shifted to Th2 polarized immunity at 5-6 weeks. This was shown clearly in schistosomeinfected yellow cattle, and was similar to the shift observed in other schistosome-susceptible hosts such as humans and mice [31]. Previous reports have suggested that CD ${ }^{+}$ $\mathrm{T}$ cells may erode the Th2 cell population steadily during chronic infection, which results in a reduced inflammatory reaction in murine schistosomiasis [34]. In water buffalo, the percentage of $\mathrm{CD} 8^{+} \mathrm{T}$ cells was always significantly higher than that in yellow cattle; the level of IFN- $\gamma$ was low in pre-infected animals, increased during early infection $(2 \mathrm{w})$, then decreased at $4 \mathrm{w}$ and $7 \mathrm{w}$ post infection. The IL-4 level was high in pre-infected water buffalo, then decreased post infection, and was at a very low level $7 \mathrm{w}$ post infection. No obvious shift of Th1-type to Th2-type polarized immunity was observed in water buffalo after infection with schistosomes. In addition, there were few egg granulomas and little pathological damage was seen in schistosome-infected water buffalo.

\section{Conclusion}

In this study, the development of schistosomes in yellow cattle and water buffalo, as well as the pathological and immunological differences between the two hosts post infection with $S$. japonicum were compared and have been discussed. We confirmed that yellow cattle were more suited to the development of S. japonicum than water buffalo, and more serious pathological damage was observed in yellow cattle than in water buffalo after animals were infected with schistosomes. Immunological analysis suggested that $\mathrm{CD} 4^{+} \mathrm{T}$ cells might be an integral component of the immune response and might associate with worm development in yellow cattle and Th1 dominated the immune response during early infection, then the response shifted to Th2-type polarized immunity at 6-7 weeks, but no obvious shift of Th1-type to Th2-type polarized immunity was observed in schistosomeinfected water buffalo. These results provide valuable information for increasing understanding of why schistosomes grow better and cause more serious pathological damage in yellow cattle than in water buffalo, and for the design of vaccines for the control of this important zonnnotic disease. Further elaboration of the mechanism of self-cure phenomen in water buffalo could be important for schistosome vaccine research and application.

\footnotetext{
Acknowledgements and funding

We thank Jinbiao Peng, Bin Zhao, Min Zhang, Fanji Guo(Shanghai Veterinary Research Institute), Hua Yu and Liang He(Animal Schistosomiasis Control Station, Agriculture Department of Jiangxi Province) for help with the animal experiment. We thank Yanli Zhang and Ying Li for assistance with the experiment. We thank Dr. Yamei Jin for helpful discussions. This work was supported by the National Science\&Technology Major Project (No.2008ZX10004-011; No.2012ZX10004220- 008); the National Basic Research Program(No.2007CB513108).
}

\section{Authors' contributions}

Conceived and designed the experiment: YJM and LJ. Performed the experiments: YJM, FZQ, SYJ, LJM, HY, LH, LK. Contributed materials/revised manuscript: FXG, FZQ, YCX. Wrote the paper: YJM and LJJ. All authors read and approved the final manuscript.

\section{Competing interests}

The authors declare that they have no competing interests.

Received: 3 November 2011 Accepted: 13 March 2012

Published: 13 March 2012

\section{References}

1. Hao $Y$, Zheng H, Zhu R, Guo JG, Wang LY, Chen Z, Zhou XN: Schistosomiasis situation in People's Republic of China in 2009. Chin J schisto Control 2010, 22(6):521-527.

2. McGarvey ST, Zhou XN, Willingham AL, Feng Z, Olveda R: The epidemiology and host-parasite relationships of Schistosoma japonicum in definitive hosts. Parasitol Today 1999, 15(6):214-215.

3. He YX, Salafsky B, Ramaswamy K: Host-parasite relationships of schistosoma japonicum in mammalian hosts. Trends Parasitol 2001, 17(7):320-324.

4. Jiang Z, Zheng QS, Wang XF, Hua ZH: Influence of livestock husbandry on schistosomiasis transmission in mountainous regions of Yunnan Province. Southeast Asian. J Trop Med Pub Health 1997, 28(2):291-295.

5. Wu K: Schistosomiasis japonica among domestic and wild animals in China. Chin Vet J 1957, 3:98-100.

6. Dai ZJ, Yan JP: Study on the epidemiology of schistosomiasis japonica of mountainous area animals in Sichuasn Province. Acta Veterinaria et Zootechnica Sinica 1992, 23(1):87-91, In Chinese.

7. Zheng J, Guo JG: The position of animal hosts in schistosomiasis transmission in China. Chin J Zoonoses 2000, 16(6):87-88.

8. Cheng PC, Tsaihong JC, Lee KM: Application of recombinant Sjc26GST for serodiagnosis of Schistosoma japonicum infection in water buffalo (Bos buffelu). Vet Parasitol 2007, 150(4):314-320

9. Shen W: Review and suggestion of control of animal schistosomiasis in China. Chin J Schisto Control 1992, 4:82-84.

10. Liu SX, He YK, Song GC, Luo XS, XU YX, McManus DP: Anti-fecundity immunity to Schistosoma japonicum induced in Chinese water buffaloes (Bos buffelu) after vaccination with recombinant $26 \mathrm{kDa}$ glutathione-Stransferase (reSjc26GST). Vet Parasitol 1997, 69(1-2):39-47.

11. He YX, Xu ST, Shi FH, Shen W, Hsü SYL, Hsü HF: Comparative studies on the infection and maturation of schistosoma japonicum in cattle and buffaloes. Current Zoology 1992, 38(3):266-271, In Chinese.

12. He YX, Yang HZ, Mao SB: Host specificity of schistosomiasis japonica I: The developmental rates, distribution and survival in mammals. Chin Med J 1960, 46:470-475.

13. Da'Dara KA, Li YS, Xiong T, Zou J, Williams GA, McManus DP, Zheng F, Yu XL, Gray DJ, Harn DA: DNA-based vaccines protect against zoonotic schistosomiasis in water buffalo. Vaccine 2008, 26(29-30):3617-3625.

14. Liu J, Mengel K, Friedberg KD: In vivo effects of fluconazole on lymphocyte subpopulations of the thymus and spleen in mice: Flow cytometry analysis. Int J Immunopharamacol 1996, 18(8-9):449-457.

15. Berner B, Akca D, Jung MD, Muller GA, Reuss-Borst MA: Analysis of Th1 and Th2 cytokines expressing $\mathrm{CD} 4^{+}$and $\mathrm{CD} 8^{+}$Tcells in rheumatoid arthritis by flow cytometry. J Rheumatology 2000, 27(5):1128-1135.

16. Smith JH, Lichtenberg FV: The Hoeppli phenomenon in schistosomiasis. II. Histochemistry. Am J Pathol 1967, 50(6):993-1007.

17. Luo XF, Lin SY, Lin ZY, Zhang CF, Wu WR: Observation of the sulf-cure phenomenon of water buffalo infection with Schistosoma japonicum. Chin J Vet Sci Technol 1988, 8:42-44.

18. LV MY LIYF, Lin DD: The self-cure phenomenon in buffalo and pig infected with Schistosoma japonicum and its mechanism. Int J Med Parasit Dis 2010, 37(3):184-188.

19. Zhang JA, Deng SS, Yu LS, Luo L, Chen LS: Animal schistosomiasis epidemiological survey and analysis. Chin Vet J 1984, 2:28-31.

20. Zhang JZ: Study on the epidemic situation and controlling methods of Schisosomiasis of Mountainous Area in China. Chin J Parasitol Parasitic Dis 1985, 3:301-303.

21. Dai ZJ, Yan JB, Mao GQ, Xie ZM: Studies on the epidemiology and controlling techniques of schistosomiasis of mountainy livestock in Sichuan Province. Scientia Agricultura Sinica 2006, 39(3):620-626, In Chinese. 
22. Jiang WB, Hong Y, Peng JB, Fu ZQ, Feng XG, Liu JM, Shi YJ, Lin JJ: Study on differences in the pathology, $T$ Cell subsets and gene expression in susceptible and non-susceptible hosts infected with Schistosoma japonicum. PLoS One 2010, 5(10):e13494, doi:doi:10.1371/journal. pone.0013494.

23. Peng JB, Gobert GN, Hong $Y$, Jiang WB, Han HX, McManus DP, Wang XZ, Liu JM, Fu ZQ, Shi YJ, Lin JJ: Apoptosis governs the elimination of schistosoma japonicum from the non-permissive host Microtus forti. PLoS One 2011, 6(6):e21109, doi:doi:10.1371/journal.pone.0021109.

24. Doenhoff M, Musallam R, Bain J, McGregor A: Studies on the host-parasite crelationship in Schistosoma mansoni-infected mice: the immunological dependence of parasite egg excretion. Immunology 1978, 35(5):771-778.

25. Davies SJ, Grogan JL, Blank RB, Lim KC, Locksley RM, McKerrow JH: Modulation of blood fluke development in the liver by hepatic CD4+ lymphocytes. Science 2001, 294(5545):1358-1361.

26. Harrison RA, Doenhoff MJ: Retarded development of Schistosoma mansoni in immunosuppressed mice. Parasitol 1983, 86(3):429-438.

27. Amiri P, Locksley RM, Paralow TG, Sadickt M, Rector E, Ritter D, McKerrow $\mathrm{JH}$ : Tumour necrosis factor a restores granulomas and induces parasite egg-laying in schistosome-infected SCID mice. Nature 1992 356:604-607

28. Houpt ER, Glembocki DJ, Obrig TG, Moskaluk CA, Lockhart LA, Wright RL, Seaner RM, Keepers TR, Wilkins TD, Petri WA Jr: The mouse model of amebic colitis reveals mouse strain susceptibility to infection and exacerbation of disease by CD4+ T Cells. J Immunol 2002, 169(15):4496-4503.

29. Lamb EW, Walls CD, Pesce JT, Riner DK, Maynard SK, Crow ET, Wynn TA, Schaefer BC, Davies SJ: Blood fluke exploitation of non-cognate $\mathrm{CD}^{+} \mathrm{T}$ cell help to eacilitate parasite development. PLoS Pathog 2010, 6(4): e1000892, doi:10.1371/journal.ppat.1000892.

30. Kalinkovich A, Weisman Z, Greenberg Z, Nahmias J, Eitan S, Stein M, Bentwich RZ: Decreased CD4 and increased CD8 counts with T cell activation is associated with chronic helminth infection. Clin Exp Immunol 1998, 114(3):414-421.

31. Pearce EJ, MacDonald AS: The immunobiology of schisosomiasis. Nat Rev Immunol 2002, 2:499-511.

32. Cheever AW, Hoffmann KF, Wynn TA: Immunopathology of schistosomiasis mansoni in mice and men. Immunol Today 2000, 21(9):465-466.

33. Wilson MS, Mentink-Kane MM, Pesce JT, Ramalingam TR, Thompson R, Wynn TA: Immunopathology of schistosomiasis. Immunol Cell Biol 2007, 85:148-154.

34. Chensue SW, Warmington KS, Hershey SD, Terebuh PD, Othman M, Kunkel SL: Evolving T cell responses in murine schistosomiasis: T cells mediate secondary granulomatous hypersensitivity and regulated by CD8+ T cells in vivo. J Immunol 1993, 151(3):1391-1400.

doi:10.1186/1746-6148-8-25

Cite this article as: Yang et al:: Comparison of worm development and host immune responses in natural hosts of schistosoma japonicum, yellow cattle and water buffalo. BMC Veterinary Research 2012 8:25.

\section{Submit your next manuscript to BioMed Central and take full advantage of:}

- Convenient online submission

- Thorough peer review

- No space constraints or color figure charges

- Immediate publication on acceptance

- Inclusion in PubMed, CAS, Scopus and Google Scholar

- Research which is freely available for redistribution

Submit your manuscript at www.biomedcentral.com/submit
Biomed Central 